\title{
Burdens of Proof and the Case for Unevenness ${ }^{1}$
}

According to Bill Lycan:

Compatibilism, not just about free will but generally, on any topic, is the default. For any modal claim to the effect that some statement is a necessary truth, I would say that the burden of proof is on the claim's proponent. A theorist who maintains of something that is not obviously impossible that nonetheless that thing is impossible owes us an argument. (2003, p. 109)

Similar claims might be made about the presumption of innocence from penal law, the principle of indifference from probability theory (Keynes 1921, p. 42), atheism (Scriven 1966, p. 88), the proposition that there is a material world (Berkeley 1971, pp. 241-242), or the claim that a building site is safe to visit. With respect to each, an uneven burden of proof distribution has been alleged. Moreover, contemporary argumentation theorists, legal theorists and others routinely posit uneven distributions to account for a wide range of phenomena. Nevertheless, Tim Dare and Justine Kingsbury have argued in a paper about unevenness "that legitimate differential allocation is much less common than is typically supposed. (2008, p. 516) Of course, what "an allocation of unevenness" would amount to depends on what a burden of proof is taken to be. We will defend a distinction between two sorts of burden, each with its own criteria for unevenness. We think that our distinction illuminates methodological discussions about unevenness and specific contentions (such as Lycan's) about uneven distributions. It also also provides a framework within which the insights that Dare and Kingsbury offer can be reconciled with the standard view, which is that uneven allocations are ubiquitous.

To a first approximation, having a burden of proof is being under an obligation, generated by the norms of rationality, argumentation, or some institution, to support one's view. Presumably, to have a heavier burden than another reasoner is to be either under a greater obligation, or obliged to do more supporting.

Douglas Walton writes: "Burden of proof is characteristically linked to the problem of an agent who must decide on a course of action or inaction in a rapidly changing, complex particular situation where certain knowledge, or even probable knowledge, cannot be acquired in time to make the best decision." (Walton 1988, p. 242) Human decision-makers have limited time, energy, predictive ability and cognitive power, so their searches for information and their deliberations about what to think and do are limited in duration, complexity and informedness. They are fallible and susceptible to systematic errors and biases. "Very often, ... an agent must act on the basis of plausible presumptions about what can reasonably be expected to happen in the given situation, based on usual expectations, customary routines, and common sense understanding of institutions, functions, and familiar sequences of actions.” (Walton 1988, p. 242) Allegedly, reliance on such factors can often be expected to result in an uneven burden of proof distribution - one in which burdens of unequal weight are associated with competing positions or with competing attitudes towards a proposition. ${ }^{2}$

But can such a thing happen? Here is a sceptical line of thought. The aims of deliberation are best served if each party assigns credence to a proposition in proportion to the total evidence available for it. If the evidence available to a particular deliberator

\footnotetext{
'We would like to thank Tim Dare, Justine Kingsbury, Fred Kroon, Immi Patterson, Glen Pettigrove, Chris Tucker, Konni Woods and three anonymous reviewers for detailed comments on various versions of this paper. We would also like to thank the audience at the 2008 meeting of the Australasian Association of Philosophy (New Zealand Division).

To save space, we will sometimes write as though burdens of proof attach to propositions, rather than to their real or imagined supporters.
} 
suggests, to some extent, that it is unclear whether the proposition is true or false, that deliberator should, to that extent, remain agnostic about its truth-value. If there is disagreement among deliberators about how to assign degrees of credence to a proposition, each party to the disagreement should have evidence for its view. So how could it be rational, as Lycan alleges, to require a more robust case from those who settle on one truth-value for a proposition than is required from those who settle on the other?

Here is a rejoinder. There are clearly some contexts in which the proponents of a view are not required to provide as compelling a case as those who reject it. To the extent that a view is widely-held, obviously true, or endorsed by the relevant authorities, we often do not require a proponent of that view to argue for it, though one who rejects it is surely required to argue against it, if we are to take such rejection seriously. If you remark that dinosaurs are extinct, I normally shouldn't ask you to furnish me with evidence. If I reject what you assert, though, you are surely entitled to ask me why. Here we require a more robust case from those who settle on one truth-value for a proposition than is required from those who settle on the other.

There is, we maintain, no tension between the sceptic and the respondent. Each appeals to a different sort of requirement, corresponding to a different sort of burden. We shall say that having an attitudinal burden means being required to possess sufficient evidential support for one's position. Lycan, interpreted as invoking an attitudinal burden, is claiming, very controversially, that if something is not obviously impossible, one should take it to be possible, unless one has decent evidence to the contrary; in particular, one can maintain this position without possessing any evidence for it and this is what it means for the burden of proof to be entirely on the incompatibilist.

Some writers' characterisations of unevenly distributed burdens of proof certainly suggest something like the attitudinal conception. Richard Whately wrote: "According to the most correct use of the term, a "Presumption" in favour of any supposition, means, not ... a preponderance of probability in its favour, but, such a pre-occupation of the ground, as implies that it must stand good till some sufficient reason is adduced against it; in short, that the Burden of proof lies on the side of him who would dispute it ..." (p. 112) ${ }^{3}$ Dare and Kingsbury (2008) almost certainly assume an attitudinal conception, citing Berkeley (1971, pp. 241-242), Reid (1863, pp. 230-234) and Scriven (1966, p. 88), amongst others, to justify their take on the burden of proof. Dare and Kingsbury are of special interest because their paper is about unevenness. They refine the sceptical line of thought mentioned earlier: they argue that legitimate uneven distributions of the burden of proof occur only under special conditions and that when a reasoning or argumentation is aimed solely at discovering the truth about some matter, we should expect an even distribution. It will soon become clear that if indeed they have attitudinal burdens in mind, we agree. However, most theorists hold that there is much more unevenness out there and we suspect that this is because they are working with a very different conception.

Accordingly, we shall say that having a dialectical burden means being required to provide sufficient evidential support for one's position as part of a deliberative process. Lycan, interpreted now as invoking a dialectical burden, makes the following claim. Given the evidence currently available to participants in metaphysical debates about things that are not obviously impossible, they should (a) vote that such things are possible, if the election is held today and (b) not bother to garner more support for this position, until

However, in the writings of Whately (and also of Thomas Reid), it is common sense that furnishes us with many presumptions. Hence, arguably, common sense gives us sufficient (rather than no) evidential support according to these authors and this undermines the idea that they are invoking the attitudinal conception when they endorse uneven burdens. 
somebody tells them something new about why it might be false. In short, given the current state of metaphysics, supporters of this position need not provide any more supporting arguments until their opponents do and this is what it means for the burden of proof to be on the incompatibilist. The claims made by Dare and Kingsbury about burden of proof distributions do not apply, given the dialectical conception. Unlike distributions of the attitudinal burden, uneven distributions of the dialectical burden regularly occur because they further the aims of deliberation, even in contexts where the quest for truth is the sole deliberative aim, rather than merely a means to some different deliberative end.

There are attitudinal burdens because people should think and do things for adequate reasons. An attitudinal burden is a requirement to possess sufficient evidential support for one's thoughts and actions; its weight corresponds to the amount of evidential support required. There are dialectical burdens because people should reason and argue effectively and efficiently. A dialectical burden is a requirement to provide sufficient evidential support for a position; its weight corresponds to the work involved in providing the support. ${ }^{4}$ In what follows, we describe the criteria for unevenness associated with each burden. We suggest that the uncertainty, indeterminacy and controversy regarding conditions under which a burden of proof is uneven might diminish if something like our distinction is recognised. First, though, we elaborate the distinction itself in more detail.

\section{Possessing Reasons and Providing Reasons: Two Distinct Burdens}

Burdens of both sorts are attributable to propositions, or by extension, to agents who entertain them, relative to what we will call contexts of deliberation. We will understand deliberation as the process that occurs whenever mental activity, conscious or otherwise, is involved in decision-making, broadly construed. This includes deciding, or at least trying to decide, what to believe, how plausible a proposition is, whether to adopt a view, what to do and how prudent a course of action is. Deliberation about some decisions happens entirely inside an individual's mind, but some is conducted by groups. ${ }^{5}$ Some deliberation takes a while and involves the entertaining and weighing of opposing viewpoints. Verbal or other communicative behaviour may be involved in deliberation to express, clarify, precisify, or coordinate contributions. Indeed, deliberation is sometimes conducted via verbal exchanges: perhaps in soliloquy, in face-to-face discussions, or in a sequence of articles. Even when there is no linguistic or illocutionary element and only one deliberating agent, an extended deliberative process may have many of the features of a conversation, especially as conceived of by Grice. ${ }^{6}$ There are more and less orderly ways to deliberate, more and less effective ways to signpost the current state of deliberative play, more and less efficient ways to approach the deliberative goal and so on. ${ }^{7}$

\footnotetext{
${ }^{4}$ We chose "attitudinal" because, as will become clear, the relevant burden is to meet some standard of evidence that is required if one is to hold a particular cognitive attitude towards a proposition to such as believing it, or conjecturing that it is true. We chose "dialectical" because the relevant burdens arise in reasoning and argumentation that involves weighing the evidence for and against a proposition, or the evidence for competing propositions. Such a process is dialectical in a very general sense. Our use of the word is not associated with any more specialised use of it by argumentation theorist such as, for instance, to describe a specific approach to argumentation.

${ }^{5}$ In some group deliberation, individual agents assume roles, such as that of an arbiter, or that of a persuader; in others, there is a spirit of joint inquiry. Some groups, such as those you find in protracted trade negotiations, are large or volatile.

${ }^{6}$ Grice would include the very formalised or ritualised interactions that constitute legal proceedings, public meetings and parliamentary debates among conversations.

We remain neutral on whether deliberation, as characterised here, is always representable as some kind of discourse or dialogue. Note however that unlike some argumentation theorists (e.g. Douglas Walton), we
} 
Every episode of deliberation occurs in a context with its own unique features, because there are different agents who deliberate about different things, in different ways, on different occasions, under different constraints. Nevertheless, useful generalisations can often be made across contexts with significant common features: the type of decision being made, or the institutional setting within which the deliberation occurs may play an important role in structuring, informing, or constraining the deliberation in those contexts and may thus be worthy of theorists' attention. Deliberation about whether to find the accused guilty, wherever and whenever it occurs, is characterised by many common features that distinguish it from deliberation about what colour to paint the drawers, or whether one ought to believe in God. Such differences show up in, among other things, the norms governing the distributions of the burdens we are discussing. Certain norms are peculiar to particular sorts of context, such as legal, or scientific contexts. Within these, we can sometimes distinguish norms for subtypes, such as public or private law. In addition, some of the features peculiar to individual contexts, such as the amount of time available for deliberation, or the precise cost of making a bad decision, may influence the way burdens are distributed among deliberators in those contexts. In describing our two types of burden, we will illustrate with general constraints that clearly affect distributions in a range of similar contexts, as well as with factors that operate in specific contexts.

Having an attitudinal burden, with respect to a certain proposition, means being required to possess an attitudinal warrant: that is, some evidential support for the proposition that meets a contextually determined standard. ${ }^{8}$ One is subject to such a requirement when one has, roughly speaking, some sort of positive attitude, or stance, towards the proposition: when, for instance, one gives it high credence, or entertains it as a hypothesis worth exploring, or decides to behave in a way that would be costly, if it were false, or beneficial, if it were true. ${ }^{9}$ The standard that evidential support is required to meet - and hence, how heavy that agent's attitudinal burden is in the context - depends, to some extent, on which of these, or other, activities is being engaged in - that is, on the purpose served by deliberating about the proposition, in the context. It also depends on practical constraints on deliberation, agreements and conventions about what counts as relevant, undefeated evidence in the field to which the deliberation belongs and other contextual factors. Often, these factors will not fix a precise standard of proof and it will not always be possible to compare the weight of different burdens. Typically, however, deliberators who are curious about whether a proposition is true may reasonably hold themselves to a higher standard (and thus shoulder a heavier attitudinal burden) than a deliberator who merely wishes to decide whether the proposition is a hypothesis that is worth exploring further. Likewise, deliberators who contemplate an action that is extremely risky, if the proposition is false, should usually be held to a higher standard (shoulder a heavier burden) if they are gathering evidence for the truth of the proposition, than they would be if they were gathering evidence for its falsity. Certainly agents who

do not use the word "deliberation" to delineate a type of communicative act or exchange.

We are not wedded to any particular idea of what makes for evidential support, but here are some very rough terminological constraints. One has evidential support for a proposition to the extent that one has grounds (or reasons) for regarding it as likely. Very roughly, to the extent that such grounds are regarded as credible, the proposition under scrutiny is regarded as credible. The evidential support is sufficient if it satisfies a contextually relevant criterion (a standard of proof) and we mention several examples of such criteria below. We will assume that they are, or correspond to, various inferential and epistemic norms derived from logic, probability theory, accounts of default, or legal reasoning and so on. (Readers who are uncomfortable with this assumption can substitute their own preferred story about norms of reasonableness.)

Negative and committed neutral attitudes or stances also attract attitudinal burdens. A negative attitude towards a proposition is a positive one towards its negation. A committed neutral attitude towards it is a positive attitude towards the proposition that it is not appropriate to have a view. 
meet the standard of proof only if they have available a valid argument with self-evident premises shoulder a heavier attitudinal burden than one who is only required to be justified beyond reasonable doubt. Lighter still is the attitudinal burden to support a proposition on the balance of probabilities. A weightless burden (that is "no burden") falls on one who is rationally permitted to have no evidence for a position. (The compatibilist enjoys this luxury, if Lycan is right and if he has attitudinal burdens in mind.)

The weight of an attitudinal burden carried by a supporter of some proposition may change during some process of fact-finding or deliberation. I may believe that my product is reliable on the grounds that it meets some industry standard. However, if subsequent research shows that a rival product meets a more stringent standard, it may become reasonable for me to adopt this as a new benchmark and apply the new standard when considering whether my product is indeed reliable. If so, I now shoulder a heavier attitudinal burden, with respect to the proposition that my product is reliable, because the evidential support I have for it must meet a higher standard before I can believe it.

However, an attitudinal burden cannot be discharged or shifted. I might meet the standard, because sufficient evidence for my view is available to me. The requirement that I meet the standard of proof persists even when I meet it: the fact that I have what is required does not stop it from being required. Whether I have it or not has to do with whether it is appropriate for me to regard a certain proposition in a particular way and not with what is appropriate for another agent, or how another proposition ought to be regarded. Plausibly, then, philosophers, legal theorists and others who hold that burdens of proof can be discharged or shifted ought not to be invoking the attitudinal conception. ${ }^{10}$

We can, of course, define a variant of the attitudinal conception according to which one has a burden with respect to a proposition if one has an attitudinal burden and is yet to meet the standard of proof. There is an uneven distribution of such a burden in any context where a proposition's devotees have sufficient support for their view, while some of its detractors lack sufficient support for their view. This can happen, regardless of whether or not consideration of the proposition is primarily aimed at finding the truth. So unlike the attitudinal conception, this variant does not invite the scepticism that Dare and Kingsbury air about the prevalence of uneven burdens. Furthermore, if things change in our imagined scenario, so that the devotees' grounds are undermined or a detractor's are sufficiently boosted, for instance, we might be entitled to talk of shifting or discharging a burden. Hence, this variant may seem like a conception of the burden of proof with which many contemporary theorists operate.

We doubt that it is. There is a tendency in the literature to regard Whately as an important architect of the principles governing the burden of proof. Accordingly, we detect, especially in Walton's (1988) work, a tacit acceptance of the possibility that in some contexts, deliberators who lack evidential support for their views nonetheless shoulder no burden. This offends against both the attitudinal conception and our new variant of it. ${ }^{11}$ Is there a usable conception of the burden of proof that allows for such

\footnotetext{
10 Examples from philosophy include: Brown 1970, p. 82; Rescher 1977, p. 28 and p. 105; Rescorla 2009, p. 86; and Walton 1988, p. 239 and p. 246. Examples from legal theory include Hay and Spier 1997, p. 415 and p. 427; Pauwelyn 1998; and Walton 2002, p. 268. Examples from argumentation theory include Bailenson and Rips 1999, p. 4, p. 9, p. 12 and p. 14; Gordon, Prakken and Walton 2007, p. 876, pp. 878880, p. 887 and p. 893; and Prakken, Reid and Walton 2005, pp. 115-7 and p. 123. There are many more. Of course, "discharging" and "shifting" in these writings might not always be intended to refer to a change. "Discharging the burden of proof" might instead mean: "having sufficient evidential support" and "shifting the burden of proof" might mean something like: "demonstrating that another party, rather than oneself, turns out to have had the heavier burden all along”. So understood, an attitudinal burden can be discharged or shifted, but these are unhappy metaphors.

"Henceforth, we will not mention that variant in the text, but the way it operates in various contexts of deliberation can be recovered from a consideration of the way that the attitudinal conception operates in
} 
contexts, posits dischargeable, shiftable burdens and allows for uneven distributions, even when truth is a primary aim? We think there is and that it captures the role allotted to burdens of proof by many of today's theorists.

Whereas having an attitudinal burden with respect to some proposition means being required to possess evidential support for it that meets some standard of proof, having a dialectical burden with respect to a proposition means being required to provide evidential support for it that meets some standard of proof, in order to contribute to an on-going, deliberative process.

To say of some stage in an extended deliberative process that I have a dialectical burden at that stage is, roughly, to say that an appropriate next move at that stage, or an appropriate long-term strategy to be at least partially implementing at that stage, would be for me to supply reasons for some view - reasons that meet a standard of proof appropriate to the aims of the deliberation. ${ }^{12}$ If I have an attitudinal warrant, I may supply such reasons by making it available to all deliberators. ${ }^{13}$ However, if I am required by another party to defend the proposition that I am in pain, and if my attitudinal warrant for it is strictly phenomenological, I cannot make it available. I might instead produce evidence that I have such a warrant, by writhing pathetically. Alternatively, I might provide evidential support that is independent of my own warrant, perhaps by reminding my challenger that a girder fell on me.

I can shoulder an attitudinal burden without a corresponding dialectical one. I might, for instance, be convinced that I am in pain (and hence, rationally required to have evidential support for my conviction), in a context where I am not required to deliberate about anything to which this conviction is relevant (and hence, not required to contribute evidential support for it to any deliberative process). I will not need to give voice to any evidence that I am in pain, or run through that evidence in my head at crucial moments. Conversely, I might have a dialectical burden without a corresponding attitudinal one. I might know that I am not in pain (and hence not be rationally required to have evidential support for the proposition that I am in pain), but be required to persuade some challenger that I am in pain - perhaps in order to show a third party how gullible the challenger is.

The weight of a dialectical burden is the degree to which one must exert oneself in order to meet one's justificatory dialectical obligations. This could depend on several factors, including the following three: (i) how strict the standard of proof is the sole determiner of weight on the attitudinal conception); (ii) how pressing the obligation to meet that standard is; and (iii) how easy it would be for a reasonably well-informed and well-endowed deliberator to meet the standard. Even if we restrict ourselves to contexts in which the balance of probabilities is the strictest standard one could reasonably require, these vary with respect to the second factor, the importance that attaches to the question of whether and how the matter is resolved. Arguably, more is at stake in a civil case involving a contractual dispute than when a teacher is deciding whether to give a student an extension. Meanwhile, if we restrict ourselves to criminal cases where the standard is proof beyond reasonable doubt, these vary with respect not only to the second but also to

\footnotetext{
those contexts.

${ }^{12}$ I may shoulder several dialectical burdens at once, because of the deliberative context in which I find myself. I may be required to provide sufficient evidential support for $p$, in order to provide sufficient evidential support for $q$, in order to provide sufficient evidential support for the proposition that my former self was wrong to deny that $q$.

13 The difference between merely having an attitudinal warrant and also being required to make it available is like the difference between being required to have a visa in a foreign country and being required to display it. I need a visa to be in the USA. I am not required to carry it with me when I walk on frozen Lake Carnegie, but I am sometimes required to display it at Newark airport.
} 
the third factor: the obligation attached to the burden might be easier to meet in one case (because the prosecution has access to a smoking gun) than in another (where the prosecution alleges, for instance, that the defendant administered a toxin that takes twenty years to surface). ${ }^{14}$

A dialectical burden can be discharged, shifted or redistributed. If my drill sergeant insists that I am not in pain, there may be a burden on me to produce an argument for my contrary view. If I provide one, by reminding him about the girder, this information becomes available to him and I may have met my dialectical obligation, to some extent. If so, I have discharged, or at least, lightened, my burden. If he persists in his view, there may now be a burden on him to produce some evidence for it. If so, we can say that the dialectical burden has shifted to him or been redistributed.

Claims about who has a dialectical burden in much deliberation (outside of the court room, the public meeting and the like) and about how heavy it is are akin to the heuristics that govern how normal conversation runs, such as Gricean maxims and guidelines like:

- If somebody asks you a question, answer that question immediately.

This principle recommends a standard response, but alternative continuations of the conversation are appropriate sometimes, despite the heuristic. I might say: "Let's collect some more questions and then I'll answer them all at once." Or I might say: "Let me respond to your question with a question. That's what Jesus would do." Similarly, in many contexts, claims about dialectical burden assignments are heuristics that often, but not always, facilitate efficient, orderly deliberation and render that deliberation conducive to its aim. ${ }^{15}$ They are not hard-and-fast principles that are necessary for rational deliberation. They may be difficult or impossible to formulate precisely. (For example: it will often be inappropriate to specify, for a particular stage in a deliberative process, a precise standard of proof that particular agents must meet before discharging the dialectical obligations incumbent on them at that stage.) Of course, heuristics and principles other than those associated with dialectical burden assignments are also in play when we consider how to begin or continue deliberating rationally. These include directives that flow from the aims of deliberating in particular contexts. For instance, if your goal is to persuade somebody of the truth of a proposition, you should highlight information that lends plausibility to it. They also include more general guidelines such as:

- Interpret contributions charitably; and

- Do not commit yourself to controversial positions, if you can advance the deliberative process without making such commitments.

In many contexts, the significance of these other guidelines means that we deliberate without being guided by how dialectical burdens are distributed. In some deliberation, there is plausibly no dialectical burden, because the success of the deliberation does not depend on any accurate, objective, assessment of the extent to which there is evidential support for a proposition. These include contexts where the aim is to negotiate a settlement, or persuade one party of a view. ${ }^{16}$

\footnotetext{
${ }^{14}$ The conception of relative weight developed here is intended as a way to make sense of appeals to the burden of proof in argumentation theory; it is not a claim about legal theory.

${ }_{15}$ Because of these parallels between conversation and reasoning, we think that the dialectical conception of burden of proof distributions comports well with contemporary research programmes that focus on dialogues or constructions built out of speech acts. We think this conception offers a good account of many references to burdens of proof, explicit or otherwise, in some presentations of pragma-dialectics (see, for instance, van Eemeren and Grootendorst 2004), argumentative discourse analysis (see Schiffrin 1985, p. 40), communicative action theory (see Kopperschmidt 1987) and Walton's pragmatic approach (see his 1992, p. 383). This does not mean, of course, that all of these theorists would agree with all the remarks we make about how dialectical burdens are distributed in various kinds of deliberative context.

${ }^{16}$ We could, of course, adopt a broader definition, according to which there are different sorts of dialectical
} 
Claims about dialectical burden assignments are not always mere heuristics. Some institutions, including, famously, courts of law, impose strict criteria about standards of proof and how the dialectical burden is to be allocated, presumably on the assumption that such rules are conducive to the aim of the institution. This is not a problem for the view that dialectical burden allocations are often mere heuristics. In some environments, keeping to the left while driving is a good, defeasible, mere heuristic. In others, it makes sense to have a law enjoining motorists to keep to the left. We should expect the same flexibility in the degree to which dialectical burden allocations are institutionally entrenched.

Both conceptions of burden of proof assignments preserve the insight that you only get an uneven distribution when it promotes the aims of decision-making, but, as we will show, according to the attitudinal conception, this happens only in contexts where establishing the truth of a proposition is not a primary aim, and only in some of those. The dialectical conception is more permissive.

\section{The Attitudinal Burden: When Truth is Not a Primary Aim}

Considering the evidence for and against some proposition $p$ is sometimes a means to some deliberative end other than truth. Consider, for instance, contexts in which I try to persuade you that $p$; contexts in which I try to win a dispute or a debate about whether $p$ (without necessarily persuading other contestants) $;{ }^{17}$ and contexts in which I try to decide among two or more courses of action and in which the question of which of them are worth pursuing depends on whether or not $p$ is true. We will focus on the latter sort of context in order to show that in some, but not all contexts in which truth is not the primary aim, there are uneven distributions of the attitudinal burden.

Consider contexts where our view about the plausibility of some proposition helps us to decide whether to perform some action, where safety is crucial. My brother arrives to clean the gutters, but his ladder is not long enough. ${ }^{18}$ Should he instead climb my ladder, which is long enough? He only wants to do that if he can do it safely; there is a high cost otherwise. So he becomes interested in the truth-value of the proposition that my ladder is safe and he must evaluate it under uncertainty. If he is not supplied with good enough evidence to believe that my ladder is safe, he should not climb it. ${ }^{19}$

\footnotetext{
burden associated with different deliberative aims. The sort that we are calling dialectical burdens might then be called dialectical burdens of evidential support and there would also be dialectical burdens of persuasion, dialectical burdens of negotiation and so on. Certainly, all such burdens exist. We have made a terminological choice in order to draw attention to the issues that seem to have caused puzzlement about unevenness. These have to do with the conditions under which one party is required to establish that a proposition is plausible, to some degree, whereas another party is not. If every deliberative aim directly generates a dialectical burden (and hence, something that might be called a burden of proof), there is no puzzle. Given the more inclusive definition, it is immediately obvious that there are uneven distributions of (broadly construed) dialectical burdens. There will be one, for instance, whenever I aim to persuade you of something and you do not aim to persuade me of anything, or to remain unpersuaded; in deliberative contexts of that sort, I have a (dialectical) burden (of persuasion) and you do not.

${ }_{17}$ Since I can do either of these without any personal commitment to the truth of $p$, not all of these types of context are ones in which I shoulder an attitudinal burden.

${ }_{18}$ We have adapted this case from Dare and Kingsbury 2008, pp. 508-509.

19 This does not, of course, mean that he should then regard my ladder as unsafe; he can rationally remain agnostic, or take some more nuanced intermediate position. In a variant of the case, an insurer, building contractor, or other institution stipulates that my brother may only climb my ladder if it passes a specific safety test. In this variant, the default is still that he does not climb the ladder, so there is still an uneven distribution. Notice though that if the test is not performed, or if my ladder fails the test, my brother could still, quite rationally, believe that my ladder is safe, even if he would have had even higher credence in this proposition had the ladder passed the test and even if he should not climb it.
} 
So, in this context of deliberation about the truth of a proposition, there is an uneven distribution of the attitudinal burden. Insofar as we are interested in how sensible it would be to climb my ladder, there is an attitudinal burden on anybody who takes it that my ladder is safe, but no burden on anybody who takes it that it is unsafe. We have explained this in terms of the end to which finding the truth of the proposition is a means. A lot of deliberation is like this and it is not all about safety (unless safety is construed very broadly). If you are not sure whether you want to access the in-flight entertainment, you should grab the headphones when they come past - just in case. If you are not sure whether you want to get married, you shouldn't. If you are not sure whether the car is roadworthy, you should neither buy it (caveat emptor) nor drive it. Better safe than sorry.

There is likewise an uneven attitudinal burden distribution associated with verdicts in many court proceedings. For instance, in criminal trials in some jurisdictions, if the court decides that the accused has committed some offence, the accused may lose rights that the law normally protects. Criminal law requires justification for any interference with a person's legal rights, so the jury must be sure, beyond reasonable doubt, on the basis of admissible evidence, that this imposition is justified. According to the institutional rules of these jurisdictions, if the jury is not convinced, beyond reasonable doubt, on the basis of admissible evidence, that the accused committed the offence, the accused is to be found not guilty, whether or not there is evidential support for the proposition that the accused did not commit the offence. So here again, we have an unevenly distributed attitudinal burden. And again, as with safety contexts, something is at stake that is more than, or different from, the mere truth of the proposition at issue.

We can explain the uneven distributions in the types of context described above in terms of differences in expected utility. Suppose you are deciding, under uncertainty, between two incompatible actions, $A$-ing and $B$-ing - such as climbing my ladder and not climbing it. (The point can be generalised to more than two alternatives.) Suppose that if it was rational to believe that $p$ - that the ladder is safe, for instance - it would, for this reason, be rational to $A$, and that if it was rational to believe that not- $p$, it would, for that reason, be rational to $B$ instead. Suppose too that we currently have no good reason for believing that $p$ rather than that not- $p$, and no other way of deciding whether to $A$ or to $B$. Then there is an expected utility imbalance with respect to $p$ just if it would be more rational to perform one act, say, $B$-ing, than to perform the other, because (1) reaping the benefits that $A$-ing yields if $p$ is true has less utility than avoiding the costs that $A$-ing bequeaths if $p$ is false, and (2) the costs and benefits of $\boldsymbol{B}$-ing are not so distributed.

Suppose my brother lacks a high degree of conviction in the proposition that my ladder is safe. ${ }^{20}$ Then, no matter how little or how much credence he assigns to its negation, he acts rationally by not climbing my ladder, because although he values cleaning the gutters, he values life more. Suppose there is insufficient admissible evidence that, beyond reasonable doubt, the accused committed the offence. Then the accused should be found not guilty, because although the law values the imposition of prescribed penalties on wrongdoers, it values the protection of legal rights more.

Identifying expected utility imbalance in these types of context seems to explain the uneven attitudinal burden assignments. We think we can generalise and say that in contexts of deliberation in which truth is not the primary aim, and in which there is an expected utility imbalance with respect to a proposition, the attitudinal burden with respect to that proposition is therefore unevenly distributed.

We think the converse holds too. Consider an episode of deliberation where truth is

\footnotetext{
${ }^{20}$ Decision-theoretically, the standard of proof, that is, the degree of conviction he would need in order to have a sufficiently "high conviction", depends, in this context, on the expected utilities of climbing my ladder and of not climbing it.
} 
not the primary aim and where the attitudinal burden with respect to some proposition is evenly distributed. I am running late for an appointment and unexpectedly reach a fork in the road. Should I go left, or right ${ }^{21}$ I only want to go left if I will keep the appointment that way, because if I will not, the cost of going left is high. So I become interested in the truth-value of the proposition that the appointment is to the left and I must evaluate it under uncertainty. Ceteris paribus, to the extent that incoming evidence supports this proposition, I should be inclined to go left and if the incoming evidence undermines it to the same extent, I should, to that same extent, be inclined to go right. So, in particular, if the evidence in favour of the proposition must exceed some threshold before I should go left, then, the evidence against the proposition must exceed that same threshold before I should go right. ${ }^{22}$ Any attitudinal burden with respect to the proposition that the appointment is to the left is thus evenly distributed in this deliberative context.

Correspondingly, there is no expected utility imbalance with respect to this proposition in this context. Although I am deliberating under uncertainty, I am only interested in the truth-value of the proposition because of the way that my view about it will influence my decision to go left or right and these options do not differ in their expected utility. This is evidently why any threshold above which the evidence for going left should compel me to go left is also the threshold above which the evidence for not going left should compel me to go right. We think we can generalise and say that in contexts of deliberation where truth is not the primary aim, and where there is no expected utility imbalance with respect to a proposition, the attitudinal burden with respect to that proposition is therefore evenly distributed.

\section{The Attitudinal Burden: When Truth is a Primary Aim}

We turn to contexts where our search for the truth-value of some proposition is not a means to some other end, unless the end is satisfying curiosity (about the truth of this, or some other proposition), learning facts, shunning falsehoods, "an interest-free inquiry into the state of the world" (Hahn and Oaksford 2007, p. 48), or something similar. We will not be drawn on how much, if any, such deliberation there is. ${ }^{23}$ Attitudinal burdens are always evenly distributed with respect to the propositions at issue in such contexts and there is no expected utility imbalance.

If we are interested in ascertaining the truth-value of a proposition for the sake of truth alone, we should assign it a degree of credence that is proportional to the available evidence. $^{24}$ If new evidence becomes available, we should update our assignment of credences accordingly. This will affect the probability that $p$ and the probability that not- $p$ in complementary ways: if it increases the degree of credence we assign to $p$, it decreases the degree of credence we assign to not- $p$ by the same amount. So, the case for $p$ and the case for not- $p$ are systematically related in such a way that establishing one cannot require meeting a stricter standard than establishing the other. Any attitudinal burden is evenly distributed.

\footnotetext{
${ }^{21}$ Supplement the story in whatever way you prefer to rule out other options: going backwards, going nowhere and so on.

${ }_{22}$ We do not assume that there is any such threshold (any standard of proof) in this kind of context. Plausibly, one should decide to go in the direction that is clearly supported by more evidence, however much evidence that is. Some writers, including Hahn and Oaksford (2008), would argue that this absence of a standard of proof means that there can be no burden. We will not address this issue. We restrict ourselves to considering when any burden that there might be is uneven.

${ }^{23}$ It might help to think of particle physics or mathematics, in order to conceive of it. We will offer more mundane, though controversial, examples of it in Section 5 below.

${ }^{24}$ Compare Hume in "Of Miracles” (1777), X.I.87; 1975, p. 110.
} 
Correspondingly, there is no expected utility imbalance. In a context where truth is the sole aim, we deliberate about the extent to which there are grounds for endorsing a proposition $p$, not about the extent to which there are grounds for pursuing some end to which gathering evidence about the truth-value of $p$ is relevant. Questions about the utility of pursuing an end, as compared with the utility of the alternatives, do not arise.

Combining the results of this and the previous section, we can see that uneven distributions of the attitudinal burden occur only in contexts in which truth is not the primary aim, and not in all such contexts. Where they occur, they are explained by an expected utility imbalance.

\section{The Dialectical Burden: When Truth is Not a Primary Aim}

Having a dialectical burden with respect to a proposition is being required to produce, or display evidential support for that proposition; that is, to contribute it to a process of deliberation. The question of whether a dialectical burden attaches to a proposition arises fairly naturally when it is useful to model or reconstruct the deliberative context as a sort of dialogue or idealised conversation. We think that such modelling or reconstruction is often useful and that very often it reveals unevenly distributed dialectical burdens. In particular, limitations on our knowledge and our ability to acquire it mean that we deliberate under uncertainty and this often generates unevenness. In this section, we consider why it might be generated in many contexts where truth is not the primary aim.

For a start, expected utility imbalance yields uneven distributions of the dialectical burden just as it yields uneven distributions of the attitudinal burden. We established that my brother must have grounds for believing that my ladder is safe, if it is rational for him to climb it. This is why there is an uneven distribution of the attitudinal burden. However, if we are to make sense of the idea that he is deliberating about whether to climb my ladder, his grounds must function as his reasons for deciding that the ladder is safe. We can model this requirement by reconstructing his deliberation as a sequence of moves, where each move is a making of an inference, a choosing among alternatives, or some other piece of reasoning and where the resulting sequence is like a conversation that he has with himself, or with real or imagined co-deliberators. This may or may not reflect some of the psychological processes involved in his decision, but it certainly reflects the sequence of justifications, retractions, hypothesisings and so on that we evaluate in order to evaluate the reasoning. One move in the reconstruction might be an inference from some piece of purported evidence to the proposition that my ladder is safe. To the extent that the evidence really does support that proposition, the dialectical burden has been discharged; it has, to that extent, shifted to those who would question the proposition that my ladder is unsafe. No dialectical burden attaches to that proposition before the redistribution, however, for the same reason that no attitudinal burden at all attaches to it. Because there is an expected utility imbalance, my brother should not climb my ladder unless it is rational for him to believe that it is safe. So nobody is required to contribute to the deliberation by arguing that my ladder is unsafe.

These points transfer to the deliberations of individual jurors and of the jury as a whole in criminal trials. There too, an expected utility imbalance, associated here with the relative costs and benefits of withholding legal rights, generates an uneven distribution of both burdens. Meanwhile, there is a dialectical burden that is unevenly distributed between prosecution and defense. The prosecutor is required, by the institution, to try to provide evidential support for the proposition that the accused is guilty. If the prosecution establishes this proposition beyond reasonable doubt, the dialectical burden is 
discharged. ${ }^{25}$ The defense need not provide evidential support for the proposition that the accused did not commit the crime. On one way of understanding how a verdict is reached, the role of the jury is to decide, on the basis of beliefs formed as a result of due deliberation, whether the prosecutor's burden has been discharged. ${ }^{26}$ This gives rise to the unevenness in jurors' attitudinal and dialectical burdens and we have seen how all of this unevenness can be motivated by expected utility imbalances.

In the types of context considered thus far, expected utility imbalance ultimately explains unevenness in both attitudinal and dialectical burdens. There are, however, contexts in which the attitudinal burden is evenly distributed, but the dialectical burden is unevenly distributed. This is because, although expected utility imbalance is the only explainer of unevenly distributed attitudinal burdens, there are other factors about our epistemic limitations that generate unevenly distributed dialectical burdens. Ascertaining the truth-value of a proposition, whether as a means to some other end or for its own sake, involves decisions about where to look for evidence and what useful conclusions to draw from it. These decisions are made under uncertainty by epistemically constrained agents: we cannot search everywhere for evidence and we cannot test every hypothesis that the evidence might support. We must select shortcuts intelligently. There are efficient and inefficient ways to search for truth (for instance, it is usually inefficient to cover old ground).

Because of these epistemic limitations and the compensatory strategies they inspire, there are many contexts of reasoning, solely truth-seeking and otherwise, in which proportioning our degrees of credence in a proposition to the available evidence gives rise to unevenly distributed dialectical burdens. This is because, in those contexts, attempts within the search to defend some proposition explicitly are more conducive to serving the aims of the deliberation (given the point reached in the search) than attempts to undermine it, or vice versa.

Consider again the unexpected fork in the road. We said that the attitudinal burden with respect to the proposition that the appointment is to the left is evenly distributed; I am trying to decide which way to go and I have no grounds for going left rather than right. At this stage, the dialectical burden is also evenly distributed, because I am required to provide evidential support for the proposition that the appointment is to the left as part of the deliberation to precisely the same extent that $\mathrm{I}$ am required to provide evidential support for its negation. However, suppose that I find some evidence that the appointment is to the left and that I am rightly moved by this evidence to assign high credence to that proposition. Were I to act now, I should go left. The attitudinal burden is still evenly distributed: there is no expected utility imbalance, so any evidence that should persuade me to go left, because the appointment is to the left, must meet the same standard as any evidence that should persuade me to go right, because the appointment is

\footnotetext{
${ }^{25}$ A prosecutor who is convinced, beyond reasonable doubt, that the accused is guilty shoulders a corresponding attitudinal burden. In general, though, questions about related attitudinal burdens shouldered by prosecution and defense counsels have to do with their doxastic attitudes, not with their professional obligations.

${ }^{26}$ However, the burden shouldered by a prosecutor is often called "the burden of persuasion". So another way to think about the situation is to regard the prosecutor's attempt to establish guilt, beyond reasonable doubt, as a means of persuading the jury, beyond reasonable doubt, that the accused is guilty. Since persuasion is not a solely truth-seeking endeavour, this approach gives us the same picture as the one in the text, via a different route. On both accounts, the jury is required to deliberate appropriately about the verdict. According to yet another account, the prosecutor is not required to (try to) establish anything. The aim is simply to persuade the jury, perhaps by providing sufficient evidential support, perhaps not. On this account, the prosecution has no dialectical burden (in our sense) at all, but does shoulder a dialectical burden (of persuasion) in the broader sense described in footnote 21. Clearly such a burden is unevenly distributed, since nobody in this context is required to persuade the prosecution of anything.
} 
to the right. I now possess good evidence that I should go left, but this does not stop me from requiring it. However, this new evidence redistributes the dialectical burden so that it falls more heavily on one who challenges the proposition that the appointment is to the left. There is now a presumption in favour of that proposition. This does not render it immune to challenge, but it means that any challenger should explain why we should reconsider the existing evidence.

Hence, there is a kind of deliberative inertia that is captured by the idea of a dialectical burden: the challenger must contribute countervailing evidence that not only redresses the balance, but also tips it in the other direction, before I should regard it as plausible that the appointment is to the right. ${ }^{27}$

We have now considered two aspects of our epistemic limitations that give rise, in contexts where truth is not the primary aim, to unevenly distributed dialectical burdens: expected utility imbalance, which also yields uneven distribution of the attitudinal burden in these contexts, and the more general impact of our need for efficient truth-seeking strategies. The latter also affects solely truth-seeking contexts of deliberation.

\section{The Dialectical Burden: When Truth is a Primary Aim}

We will discuss three examples of kinds of contexts where there is plausibly a deliberative process aimed solely at the truth and where the demand for efficient search strategies yields unevenly distributed dialectical burdens. ${ }^{28}$

\subsection{Type I Contexts}

Consider solely truth-seeking contexts in which a highly plausible proposition is asserted. These include contexts in which the asserter is rightly regarded as an authority, unlikely to mislead: a stranger introduces himself by saying that his name is "Chris". They also include contexts in which it is reasonable to judge that the fact-finding process culminating in the assertion is reliable (say, on the basis of past experience of similar processes): I look out the window and declare that it is raining. Also included are contexts where all reasonable steps to establish the falsity of some proposition - like the proposition that dinosaurs are extinct - have been taken and there is good reason to think that, if it were false, we would have realised that by now.

In such contexts, the dialectical burden typically falls more heavily on a party who

\footnotetext{
${ }^{27}$ What we have argued is that epistemic limitations can explain why the provision of sufficient evidential support for a proposition might redistribute the dialectical burden so that it attaches more heavily to the proposition's negation than to the proposition itself. This argument seems not to generalise to all contexts where some evidential support is provided for a proposition. Suppose I provided supporting evidence for the proposition that the appointment is to the left that made this proposition just a little more credible, in the context, than its negation. Does this cause a slight redistribution of the dialectical burden? If so, we cannot explain it in terms of the way epistemic limitations call for efficient search strategies, as we did in the contexts where there was adequate evidential support for the proposition. If one view has a slight edge over a competitor, this is not in general a reason for thinking that we should be less sensitive to incoming evidence that offers further support for the view than to incoming evidence that challenges it. We should probably not respond to such a small difference in support by tweaking our evidence-gathering strategy. So can one explain how a small shift in support ratios could usefully be construed as a small dialectical burden redistribution? We suspect not. We suspect that no useful theoretical purpose is served by allowing that a dialectical burden gets redistributed, however subtly, with every change in support ratio. Talk of redistribution plausibly only makes sense when the change in ratio is due to evidential support that meets some standard that determines what we should believe or how we should act.

${ }^{28}$ One might doubt that some or all of the deliberative contexts discussed below are solely truth-seeking. However, even if they are not, the uneven distributions in all of them can be traced to the quest for truth, even if that quest is best construed as a means to some other end.
} 
challenges the proposition than on a supporter. Plausible propositions asserted by reliable testifiers, delivered by reliable research strategies, or supported by reasonable appeals to ignorance come with a sort of guarantee. It is more reasonable to assume, than to doubt, that if a stranger says his name is "Chris", he is correct. In the contexts under discussion, it is unreasonable for deliberators to assume that the asserter lacks evidence for the asserted proposition. Challengers should not demand more evidence for the proposition without producing reasons. ${ }^{29}$ This explains why questions like: "Why should I believe that your name is "Chris"?" usually strike us as idle.

Michael Rescorla discusses scenarios that might seem to undermine our rulings on these kinds of context. According to him, these scenarios do not manifest the kind of burden distribution that we would allege. We consider two of them.

First,

"[i]f I introduce myself to a stranger at a cocktail party, it would be ridiculous for him to retort 'How do you know that your name is Michael? Justify your assertion.' I would decline to answer. ... I decline to engage my interlocutor's challenge. I refuse to enter into reasoned discourse. My refusal does not violate the norms of reasoned discourse, any more than a refusal to play chess violates the rules of chess." (2009, pp. 94-95)

For Rescorla (2009, p. 88 and p. 90), the principles governing burden of proof distributions are constitutive norms of reasoned discourse. Hence, the passage above commits him to denying that his reasonable refusal to meet his interlocutor's challenge can be construed as a recognition that he has no burden of proof. Now we agree with him that this refusal can be described as a refusal to enter into reasoned discourse about the truth of the proposition that his name is "Michael". We think, though, that this is consistent with taking it that he has no significant dialectical burden with respect to this proposition, and this might be an appropriate thing to say about some versions of the story. Maybe Rescorla asserts that proposition as part of a reasoned discourse about some other matter. Perhaps a visitor comes to the door and asks to speak to Michael. The host, who has not yet met Rescorla, announces this to his guests. Rescorla helpfully introduces himself to the host, saying: "My name is Michael". Here, his assertion is part of an attempt to establish the identity of the wanted Michael. In this context, there is deliberation about the matter of who is being summoned by the visitor at the door. Given that context, it would be inefficient, if not gratuitous, to pause over the question of whether Rescorla's name is "Michael". So, in this deliberative context, the proposition that Rescorla's (or the speaker's) name is 'Michael' need not be defended. We can describe this situation either by saying that no significant dialectical burden attaches to that proposition, in this context, or by saying that Rescorla is not engaging in reasoned discourse about the truth of this proposition (because such discourse would not advance the current deliberative project). It seems to us that nothing turns on which description is offered. The former description usefully highlights the way that dialectical burden distribution is relative to deliberative context (since the same proposition in a different

\footnotetext{
${ }^{29}$ It is not hard to think of reasons. A detective, wishing to check details, might ask me exactly how I know it is raining. If my answer disappoints, there will be reason to doubt my reliability and this may undermine the support for the proposition I asserted and perhaps redistribute the dialectical burden. The claim in the text is consistent with the possibility that the asserter does lack evidence. The heavier dialectical burden may fall on the challenger, even when the proposition's supporters lack sufficient grounds for upholding it. If I, though normally reliable, didn't look very carefully before reporting to you that it is raining (and even if you suspect this), the dialectical burden is arguably still on you, rather than me, to show that it is not raining. So we are dealing here with contexts in which someone who lacks sufficient grounds for a proposition may nonetheless lack a significant dialectical burden. As we noted in Section 1, this is the kind of context that is disallowed by both the attitudinal conception and the "lack of evidence" variant of it that we briefly considered there.
} 
context may attract a significant burden). The latter description highlights the fact that reasoned discourses are imbedded in broader conversational contexts.

Here is Rescorla's second scenario:

"In an ordinary conversational context, someone who challenges "I have a physical body" undertakes a conversational burden. But it is not a burden of proof. It is a burden of explanation. The challenger must elucidate his position, thereby helping the original speaker isolate the relevant mutually acceptable premises... Dialectical obligation does not shift from the speaker to the challenger. It expands to encompass both speaker and challenger. The challenger assumes an obligation to help the original speaker fulfill his obligation. The former obligation is parasitic upon the latter. Speaker and challenger must jointly pursue argumentative common ground, the speaker by isolating premises that support his position, the challenger by elucidating which premises he might accept or reject. The speaker's obligation persists even if the challenger does not provide the requisite assistance.” (2009, pp. 100-101)

We agree that any obligation that the speaker has persists under these circumstances. We insist, though, that if the conversational context is indeed ordinary, any such obligation, the speaker's dialectical burden, is light. The ordinariness of the context suggests that challenging her commitment to the proposition that she has a physical body wastes time: unless and until her challenger goes some way towards discharging his burden of explanation, the speaker is under no pressing obligation to produce any evidential support. So, contra Rescorla, the heavier dialectical obligation, in the form of the dialectical burden, is on the challenger, if the conversation is ordinary. However, a conversation in which a participant is prepared to discuss whether she has a physical body is not ordinary: it is one in which she has a reason for finding this metaphysical claim relevant. In such a conversation, there may well be no dialectical shift and more of a commitment to a careful inquiry that develops from premises about which all parties agree. In such a context, the speaker's dialectical burden might be substantial. In short, we think Rescorla's observations apply most readily to extraordinary conversations. This reminds us that the heaviness of a dialectical burden associated with a particular proposition is context-dependent.

\subsection{Type II Contexts}

Some other solely truth-seeking contexts in which there is typically an uneven demand on participants to provide evidential support for their views are those in which a controversial, outrageous, or revolutionary proposition is asserted. (Maybe it goes against the standard view among experts; maybe it conflicts with something that most people believe; maybe it just seems antecedently improbable.) Examples include contexts in which some alleged scientific breakthrough, such as the achievement of cold fusion, is reported. Then there are controversial propositions that have been smuggled into a complex question, as in: "Do you think my successful cold fusion experiment will get publicity?" And there are contexts where somebody alleges a conspiracy, like: "The Crimean war was faked.”

Typically, in such contexts, the dialectical burden falls much more heavily on the asserter than on any gainsayer. In other words, a natural next move in the deliberative process is an attempt to defend the proposition and such a move is, prima facie, a better contribution to group deliberation than the attempt to undermine or rebut it.

There are good reasons for the uneven distributions here. In the interests of efficiency, we should not consider an outrageous, controversial, or improbable proposition, absent some story about why it merits attention. Inevitably, the fact that a proposition bears such marks functions as prima facie evidence against it. Hence, deliberators require a defense of any such proposition if it is to be treated seriously. So, for instance, the participant 
responding to a complex question can demand evidence for the controversial imbedded proposition and has no reason for answering the question without it.

In some of these contexts, there are additional reasons for the uneven distribution. Some conspiracy theories are unfalsifiable; they cannot be rebutted conclusively. Those who allege that the Crimean war was faked can insist that all historical documentation was faked. On the other hand, there is no reason why they should not be required to justify their allegation. Requiring them to do so may advance the quest for truth, whereas seeking to falsify the theory almost certainly will not. ${ }^{30}$

\subsection{Type III Contexts}

There are also unevenly distributed dialectical burdens in certain contexts where one participant in a truth-seeking endeavour has access to publicly inspectable evidence in support of the endorsed proposition, while participants endorsing plausible, competing views do not. It is often more efficient for the former participant to share evidence with the others than for any of the others to search for evidential support for their positions. This explains why it seems sensible to ask taxpayers to provide evidence for their views about the amount of taxable income they have, rather than to ask the taxing authority for a view about their taxable income, supported by equally compelling evidence. In many jurisdictions, the taxpayer has the opportunity to file a tax return and if this is not done, or not done to the satisfaction of the authority, the authority's assessment is treated as accurate. (See Dare and Kingsbury 2008, p. 515.)

\subsection{General Remarks about the Three Types}

We think that in the three types of context above, the contexts typically exhibit uneven distributions that result from the way epistemic limitations shape orderly deliberation about what is true. Individual contexts are nuanced: the various aims that a particular deliberative process has, how some of its aims serve others and what would count as realising each aim depend on history, specific epistemic constraints, subject-matter and many other contextual factors in very complicated ways. Hence, we must expect exceptions to our rough characterisations of types of context. We consider two.

First, here is a description, by Charles Rosen (1998, p. 50), of a specific deliberative context:

"The great pianist Edward Steuermann once was approached after a concert by a man who told him that he had written an essay to demonstrate why one cannot play twelve-tone music from memory. "But I do play twelve-tone music from memory", replied Steuermann. The man, dismayed, was silent for a moment, but he finally found a solution: "You're lying", he said." (Quoted in Rescorla 2009, p. 108)

Despite any psychological pressure Steuermann might have been under to rebut this challenge, the context seems to correspond to be of Type I above: Steuermann is surely a recognised authority on his playing and need not defend his assertion. But, in fact, the

\footnotetext{
30 We are not claiming, though, that in order to equalise the dialectical burden distribution, the asserters of an outrageous, controversial, or improbable, proposition must establish its truth to the satisfaction of rational disputants. They might need to do this if they want the proposition to be credible. But something less may suffice to make it the case that the potential denier has just as much of a burden as the asserter. (Compare Godden and Walton 2007, p. 315.) Perhaps the asserters only need to explain that they got their information from a government leak, or an expert. Then it seems as though we would have moved to a more even distribution.

${ }^{31}$ This is another sort of context in which someone who lacks adequate evidential support for a proposition (perhaps the taxing authority) may nonetheless lack a significant dialectical burden. Tax collecting is plausibly not solely truth-seeking, so factors to do with the aim it serves may also shape dialectical burden considerations. Nevertheless, the factors mentioned here are relevant, whether or not the deliberation is solely truth-seeking. See Hahn and Oaksford (2007, p. 41) for a parallel discussion of product liability.
} 
weight of his burden depends on, among other things, how pressing an obligation he is under and this in turn depends on the aim of any envisaged deliberation. If the aim is for several onlookers to converge on the truth about the possibility of playing twelve-tone music from memory, Steuermann's authority can be appealed to; Steuermann and his audience can disregard the challenge. If, however, the aim is for Steuermann and his challenger to converge on the truth, some evidential support for this proposition from Steuermann is required. Indeed, whenever there is an acknowledged difference of opinion and a commitment by all parties to convergence on a common view after rational deliberation, advancing any position whatsoever on the disputed matter would seem to require accepting responsibility for defending that position if called upon to do so by another party. ${ }^{32}$ The weight of Steuermann's burden also depends on how difficult it is to discharge. If there is a piano handy and a twelve-tone piece that is familiar to all parties and if Steuermann can play it from memory, he could easily defend his honesty; his burden is then relatively light.

For a second exception to our rough generalisations above about types of context, consider again contexts where outrageous rumours are propagated. We took these to be of Type II and said that a heavy dialectical burden falls on the propagator. But in some of these contexts, the most efficient, orderly, way for truth-seeking to proceed involves someone rebutting the rumour immediately, perhaps by discrediting its source. After all, it might be important to assess the rumours plausibility swiftly, because of errors and biases to which deliberators are prone: people are often quick to believe sensational stories, or at least, to want them investigated.

\section{Conclusion}

We distinguished two conceptions of burden of proof assignment. An attitudinal burden is shouldered by those who adopt some positive attitude or stance towards a proposition, just if they are required to have evidential support for it, in that context. There is an uneven distribution of the attitudinal burden only where there is an expected utility imbalance. This happens in some, but not all, contexts in which truth is not the primary aim, and in no solely truth-seeking contexts. A dialectical burden is shouldered by those who put forward a proposition for consideration in a deliberative context just if, in that context, some reasons in support of it should be rehearsed more or less explicitly, as part of the deliberative process. There is an uneven distribution whenever the epistemic limitations of deliberators can be usefully managed if more work is required to defend one of the available positions than is required for defending another. This can happen when there is an expected utility imbalance, but it occurs in other contexts of deliberation too. Unevenly distributed dialectical burdens occur both in contexts where truth is the sole aim and in contexts where it is not.

We suspect that views like those of Lycan on compatibilism, Keynes on the Principle of indifference and Scriven on atheism, as well as the methodological observations of many argumentation theorists about uneven distributions, are more charitably and fruitfully captured by the dialectical conception even though some written presetnations of their views allow for both interpretations Certainly the burdens typically discussed nowadays are dialectical. In particular, both the burden of persuasion (or risk of nonpersuasion) and the burden of production (or burden of going forward) ${ }^{33}$ are dialectical. ${ }^{34}$

\footnotetext{
${ }^{32}$ Pragma-dialectical analysis always assumes "that argumentation is part of a critical discussion aimed at resolving a difference of opinion.” (Houtlosser 1996, p. 30) So in pragma-dialectics, asserters are always regarded as shouldering a significant burden of proof.

${ }^{33} \mathrm{~A}$ good source for understanding the adoption of these legal notions into the theory of argumentation as a
} 
We discussed the former in section 4 when we discussed criminal trials; it is a requirement to provide sufficient evidential support for a proposition to make a case for that proposition. The latter summarises various requirements that arise at different stages in a reasoning process. At one stage, the norms governing what makes for a good process of the relevant kind might demand or permit a defence of a proposition; at another stage, those norms might demand or permit a rebuttal of that proposition. At each stage, there will be a requirement to provide evidence that meets some standard (perhaps different standards at different stages), in order for the reasoning to proceed satisfactorily. ${ }^{35}$ Argumentation theorists have paid less attention to attitudinal burdens, which arise not from so dynamics of communication or deliberation, but from the requirements of rationality and the nature of our cognitive attitudes. They are relevant to argumentation, however, since when we argue, it is in order to settle the attitude that should be taken towards a proposition or course of action and an attitude is appropriate only if we possess evidential support that meets the corresponding standard.

Having said that, we have not presupposed or argued that either type of burden plays a key, or even an explanatory, role in argumentation theory. ${ }^{36}$ Our purpose has been to make sense of attributions of unevenness and debates about their intelligibility. In particular, our framework explains in detail how, even when truth is the sole aim, there can be one (attitudinal) sense in which evidence is required to meet a certain standard before a certain cognitive attitude is appropriate, but another (dialectical) sense in which evidence meeting that standard might not be required.

Because one can be required to have evidential support for a proposition that meets a standard of proof and hence shoulder a significant attitudinal burden, without being required to defend the proposition explicitly, that is, without having a significant dialectical burden, we do not need to perform the old, ground-breaking experiments and rehearse the old arguments every time we claim that some standard, cherished, well-established scientific belief is true. In the middle of deliberating about some detail of astronomy, we might have recourse to the proposition that the Earth is an oblate spheroid. The attitudinal burden is evenly distributed between supporters and detractors: parties on either side must have evidential support that meets the same standards of scientific acceptability in order to establish their position. We are, of course, rationally permitted to endorse this proposition because we have an attitudinal warrant for it in the form of Newtonian arguments that are unlikely to founder, but this does not induce a lighter attitudinal burden on oblate-spheroidists than on their detractors. However, the dialectical

type of situated communication is Ehninger and Brockriede (1962).

${ }^{34}$ Our treatment of these issues reminds us that it is wrongheaded to characterise the conditions that make for uneven burdens along lines suggested by "semper necessitas probandi incumbit ei qui agit." Whatever principles operate in particular legal systems, neither of the burdens we identify is characterised in general by, for instance, the principle that "usually one who makes an assertion must assume the responsibility of defending it." (Michalos 1969, p. 370) One who believes a proposition should do so for a reason, whether or not one asserts it, because one shoulders an attitudinal burden. Whether one must defend one's beliefs is another matter. Meanwhile, one who asserts should perhaps defend, if one's assertion is controversial, because one shoulders a dialectical burden. One need not, however, if one asserts the obvious.

${ }^{35}$ The distinction between subjective and objective burdens in German law is similarly a distinction within the class of dialectical burdens. (Likewise, Rescher's (1977, p. 27) distinction between the probative burden of initiation and the evidential burden and Walton's (1988, pp. 246-7) related distinction between the external (global) and internal (local) burden.) We suspect that all the burdens discussed in legal theory are primarily dialectical. They apparently constrain the attitudes of deliberators (juries, for instance) only indirectly, if at all. In other words, they may give rise to, but are not themselves, attitudinal burdens.

${ }^{36}$ It is open to us, for instance, to agree with Hahn and Oaksford that "the burden of proof is insufficient as an explanatory tool for the fallacy of the argument from ignorance" (2007, p. 58) and that there seems little point in attributing attitudinal burdens except where there is "a threshold degree of conviction above which an action should be adopted, given the particular utilities associated with this action.” (p. 57) 
burden is distributed unevenly between supporters and detractors. Oblate-spheroidists are typically not required to demonstrate that they have a warrant. If they were, they would be required to provide at least some arguments in support of their position and subsequent deliberation would have to assign a degree of credence to oblate-spheroidism in proportion to the adequacy of precisely those arguments.

Distinctions among different sorts of burden have proliferated in the literature. We, of course, have contributed to this proliferation, so there is some sort of burden on us to justify our two-way distinction. We hope we have discharged it.

\section{References}

Bailenson, Jeremy and Rips, Lance. 1999. Informal Reasoning and Burden of Proof. Applied Cognitive Psychology 10(7): 3-16.

Berkeley, George. 1971 A Treatise Concerning the Principles of Human Knowledge (1734). Menston: Scholar Press.

Brown, Robert. 1970. The Burden of Proof. American Philosophical Quarterly 7(1): 7482.

Dare, Tim and Kingsbury, Justine. 2008. Putting the Burden of Proof in Its Place. The Southern Journal of Philosophy XLVI: 503-518.

Ehninger, Douglas and Brockriede, Wayne. 1962. Decision by Debate. New York Dodd, Mead.

Godden, David and Walton, Douglas. 2007. A Theory of Presumption for Everyday Argumentation. Pragmatics and Cognition 15(2): 313-346.

Gordon, Thomas, Prakken, Henry and Walton, Douglas. 2007. The Carneades Model of Argument and Burden of Proof. Artificial Intelligence 171: 875-896.

Hahn, Ulrike, and Mike Oaksford. 2007. The Burden of Proof and its Role in Argumentation. Argumentation 21(1): 39-61.

Hay, Bruce and Spier, Kathryn. 1997. Burdens of Proof in Civil Litigation: An Economic Perspective. Journal of Legal Studies XXVI: 413-431.

Houtlosser, Peter. 1998. Points of View. Argumentation: An International Journal on Reasoning August, 12(3): 387-405.

Hume, David. 1977. An Enquiry concerning Human Understanding and concerning the Principle of Morals. ed. L. A. Selby-Bigge, $3^{\text {rd }}$ edn. rev. P. H. Nidditch. Oxford: Clarendon Press. 1975.

Keynes, John Maynard. 1921/1963. A Treatise on Probability. London: Macmillan.

Kopperschmidt, Josef. 1987. The function of Argumentation: A Pragmatic Approach. In Argumentation: Across the Lines of Discipline: Proceedings (Studies of Argumentation in Pragmatics and Discourse Analysis, Vol. 3), eds. Frans H. van Eemeren, Rob Grootendorst, J. Anthony Blair and Charles A. Willard, 179-188. USA: Foris Publications.

Lycan, William G. 2003. Free Will and the Burden of Proof. Royal Institute of Philosophy Supplement. 53: 107-122.

Michalos, Alex. 1969. Principles of Logic. Englewood Cliffs: Prentice-Hall.

Pauwelyn, Joost. 1998. Evidence, Proof and Persuasion in WTO Dispute Settlement: Who Bears the Burden? Journal of International Economic Law 1: 227-258.

Prakken, Henry, Reid, Chris and Walton, Douglas. 2005. Dialogues about the Burden of Proof. International Conference on Artificial Intelligence and Law. June 6-11, Bologna, Italy: 115-124.

Reid, Thomas 1863. The Works of Thomas Reid. Edinburgh: MacLachlan and Stewart. 
Rescher, Nicholas. 1977. Dialectics: A Controversy-Oriented Approach to the Theory of K. Albany: State University of New York Press.

Rescorla, Michael. 2009. Shifting the Burden of Proof?. The Philosophical Quarterly 59(234): 86-109.

Rosen, Charles. 1998. Classical Music in Twilight. Harper's Magazine. March: 50-58.

Schiffrin, Deborah. 1985. Everyday Argument: The Organization of Diversity in Talk. In Handbook of Discourse Analysis: Discourse Analysis in Society, ed. Teun A. van Dijk, 35-46. London: Academic Press.

Scriven, Michael. 1966. Primary Philosophy. New York: McGraw-Hill.

van Eemeren, Frans H. and Grootendorst, R. 1984. Speech Acts in Argumentative Discussions: A Theoretical Model for the Analysis of Discussions Directed Toward Solving Conflicts of Opinion (Studies of Argumentation in Pragmatics and Discourse Analysis, Vol. 1). USA: Foris Publications.

Walton, Douglas. 1988. Burden of Proof. Argumentation 2: 233-254.

Walton, Douglas. 1992. Non-Fallacious Arguments from Ignorance. American Philosophical Quarterly 29(4): 381-387.

Walton, Douglas. 2002. Legal Argumentation and Evidence. University Park: Pennsylvania State University Press.

Whatley, Richard. 1846. Elements of Rhetoric, 7th ed. Edited by D. Ehninger. Carbondale IL: Southern Illinois University Press. 1963 